\title{
Research on the relationship between disposable income and real consumption expenditure
}

\author{
Xueqin Wang ${ }^{\text {a, *}, ~ Y u y a o ~ H e ~ a n d ~ M e n g ~ Y a n g ~}$ \\ College of Economics, North China University of Science and Technology, Tangshan, Hebei, \\ 063000, China \\ a2421173167@qq.com
}

\begin{abstract}
Keywords: Disposable Income, Actual Consumption Spending, Co-Integration Theory, Error Correction Mode.
\end{abstract}

\begin{abstract}
Based on data from 1979 to 2013 in China, we calculate disposable income (Dinc) and actual consumption spending (ACS). Then, we build Dinc and ACS counteraction theory and error correction model by time series analysis. After further testing, we conclude disposable income is the Granger cause of actual consumption spending, but actual consumption spending is not the Granger cause of disposable income.
\end{abstract}

\section{Introduction}

Since the reform and opening up, China's economy has grown rapidly, and residents' disposable income has increased significantly. In addition, the consumption spending and consumption level of residents have greatly improved. In recent years, based on different theories, domestic scholars discussed the relationship between disposable income and real consumption spending. Tian Qing's paper proved that there is co-integration relationship between consumption and income [1]. Liu Liying used co-integration theory, ECM model and Granger causality test and so on to conclude that there is a long-term stable co-integration relationship between rural residents' income and consumption [2]. And Wang Mingxing's research showed that there is a long-term equilibrium relationship between real consumption and real income of urban residents in Shanxi Province [3]. The research above indicate that there is a high correlation between real consumption spending and real disposable income. Based on the co-integration theory of Econometrics, this paper studies the relationship between urban residents' disposable income and consumption spending in China, and it explores the dynamics and laws of change of them.

\section{Co-integration Analysis Between Dinc and ACS}

In order to study the relationship between consumption spending and disposable income, we select some indicators and collected relevant data from 1979 to 2013 in china. First, we need to get actual consumption spending (ACS). We select total consumption spending of residents (CS, 100 million yuan) and the consumer price index (CPI, 1978 as the base year, CPI of $1978=100)$. We use CPI to adjust $\mathrm{CS}$, then we got ACS.

$$
A C S=C S / C P I
$$

As for disposable income (Dinc), we select nominal gross domestic product (GDP, 100 million yuan) and total government revenue (Tax, 100 million yuan). Then we calculated by the following formula.

$$
\text { Dinc }=(G D P-T a x) / C P I
$$

\section{Co-integration Analysis Between Dinc and ACS}

To reduce the data fluctuation, we take natural logarithm of ACS and Dinc and got sequences diagram[4]. Then check the stability, and establish the following equation.

$$
\ln A C S_{t}=c_{0}+c_{1} \ln \operatorname{Dinc}_{t}+\varepsilon_{t}
$$


Last, we do equence analysis, and make timing chart. We get the two sequences are both rising, obviously not smooth. But they grow and change roughly same, which means there may be cointegration relationship between them. So we must check their single integral order[5]. If they are both integrated of order one, there may be co-integration. If the whole order is not the same, we will use the difference to make it first order singular sequence.

Among general economic analysis, most time series data are not stationary and have a certain growth trend[6]. So we shall do stationary test before co-integration analysis. According to the basic steps of unit root test, we do stationary test toward the sum. Test results are shown in table 1:

Table 1. Unit root test results

\begin{tabular}{|c|c|c|c|c|c|c|c|}
\hline Variable & $\begin{array}{l}\text { Inspection } \\
\text { form }(\mathrm{c}, \mathrm{t}, \mathrm{k})\end{array}$ & $\mathrm{ADF}$ & $\begin{array}{c}1 \% \\
\text { critical } \\
\text { value }\end{array}$ & $\begin{array}{c}5 \% \\
\text { critical } \\
\text { value }\end{array}$ & $\begin{array}{c}10 \% \\
\text { critical } \\
\text { value }\end{array}$ & $\mathrm{P}$ & Conclusion \\
\hline $\ln A C S$ & $(\mathrm{c}, 0,0)$ & 1.937 & $\begin{array}{c}- \\
3.639407 \\
\end{array}$ & $\begin{array}{c}- \\
2.951125 \\
\end{array}$ & -2.614300 & 0.9997 & $\begin{array}{c}\text { no } \\
\text { stationary }\end{array}$ \\
\hline $\mathrm{D}(\ln A C S)$ & $(\mathrm{c}, 0,0)$ & -3.355 & $\begin{array}{c}- \\
3.646342\end{array}$ & $\begin{array}{c}- \\
2.954021\end{array}$ & -2.615817 & 0.0202 & stable \\
\hline lnDinc & $(\mathrm{c}, 0,0)$ & 1.172 & $\begin{array}{c}- \\
3.639407\end{array}$ & $\begin{array}{c}- \\
2.951125\end{array}$ & -2.614300 & 0.9973 & $\begin{array}{c}\text { no } \\
\text { stationary }\end{array}$ \\
\hline $\mathrm{D}(\ln \operatorname{Dinc})$ & $(\mathrm{c}, 0,0)$ & -3.666 & $\begin{array}{c}- \\
3.646342\end{array}$ & $\begin{array}{c}- \\
2.954021\end{array}$ & -2.615817 & 0.0095 & stable \\
\hline
\end{tabular}

From table 1, for a significant level of 0.01, 0.05 and 0.1, the Mackinnon of unit root test are $3.639407,-2.951125$ and -2.614300 respectively. The value of t test statistic is 1.937 , greater than the critical value. Thus we cannot refuse H. It is shown that the lnACS sequence has a unit root and is a non-stationary sequence. Similarly, we can see that lnDinc is also a non-stationary sequence.

Then,we choose the first order difference sequence in the unit root test dialog, select intercept and difference between the 1, and got the order of $\ln A C S$ and $\ln$ Dinc sequences. From the test results in table $1, \mathrm{D}(\ln \mathrm{ACS})$ is a stationary sequence at $1 \%$ significance level. Same as the $\mathrm{D}(\ln \mathrm{Dinc})$. That is , $\mathrm{D}(\ln A C S) \sim \mathrm{I}(1), \mathrm{D}(\ln \operatorname{Dinc}) \sim \mathrm{I}(1)$.

In this paper, the equation (3) is estimated and the results are shown in table 2:

Table 2. OLS estimation results

\begin{tabular}{|c|c|c|c|c|}
\hline Variable & Coefficient & Std. Error & t-Statistic & Prob. \\
\hline C & 0.871775 & 0.059084 & 14.75495 & 0.0000 \\
\hline InDinc & 0.846128 & 0.006160 & 137.3639 & 0.0000 \\
\hline R-squared & 0.998254 & Mean dependent var & 8.940154 \\
\hline Adjusted R-squared & 0.998201 & S.D. dependent var & 0.890985 \\
\hline Log likelihood & 66.01826 & F-statistic & 18868.84 \\
\hline Durbin-Watson stat & 0.362621 & Prob(F-statistic) & 0.000000 \\
\hline
\end{tabular}

As seen from the table, despite D.W statistics is small, other statistics show that the model is ideal. Coefficient of determination after equation adjustment $R^{2}=0.998201$. It indicates the model fitting effect is good. Coefficient estimate of lnDinc can express income elasticity of consumption spending. In order to show that the sequence $\ln A C S_{t}$ and $\ln \operatorname{Dinc}_{t}$ is Co integration, we do unit root test for residual sequence, got the following formula:

$\hat{u}_{t}=\ln A C S_{t}-c_{0}-c_{1} \ln$ Dinc $_{t}$

Unit root test for $\hat{u}_{t}$. If the residual $\hat{u}_{t}$ is stationary, the sequence $\ln A C S_{t}$ and $\ln \operatorname{Dinc}_{t}$ are Co integration. Therefore, using the data, the results are as follows: 
Table 3. Residual unit root test results

\begin{tabular}{|c|c|c|c|c|}
\hline ADF Test Statistic & -4.916598 & $\begin{array}{ll}1 \% & \mathrm{C} \\
5 \% & \mathrm{C} \\
10 \% & \mathrm{C}\end{array}$ & $\begin{array}{l}\text { Jalue* } \\
\text { Value } \\
\text { Value }\end{array}$ & $\begin{array}{l}-2.6369 \\
-1.9517 \\
-1.6213\end{array}$ \\
\hline \multicolumn{5}{|c|}{$\begin{array}{c}\text { *MacKinnon critical values for rejection of hypothesis of a unit root. } \\
\text { Augmented Dickey-Fuller Test Equation } \\
\text { Dependent Variable: D(ET) } \\
\text { Method: Least Squares }\end{array}$} \\
\hline Variable & Coefficient & Std. Error & t-Statistic & Prob. \\
\hline $\mathrm{ET}(-1)$ & -0.984869 & 0.200315 & -4.916598 & 0.0000 \\
\hline
\end{tabular}

In Table 3, at the $1 \%$ significant level, the t test statistic is -4.917 , which is less than the critical value. It indicates there is no unit root in the residual sequence. That means there is a co-integration relationship between disposable income and actual consumption spending.

\section{Co-integration test and error correction model estimation}

Co-integration means a single time series data is non-stationary, but its' some line combination may be smooth. There is a long-term stable equilibrium relationship between these variables (cointegration) [7]. In this paper, we use EG two-step method to test whether variables' data are cointegration.

The equation (3) characterizes the long-run equilibrium relation of $\ln A C S_{t}$ and $\ln \operatorname{Dinc}_{t}$. We need error correction model to analyse the dynamic relationship between real consumption spending and disposable income. The following is error correction model.

$\Delta \ln A C S_{t}=c+c_{t} \Delta \ln \operatorname{Dinc}_{t}+c_{t} e c m_{t}+\varepsilon_{t}$

In the model, $e^{e c m}$ is error correction term?

$e c m_{t}=\ln A C S_{t-1}-c_{0}-c_{1} \ln \operatorname{Dinc}_{t-1}$

Then, the error correction model is estimated, and the results are shown in Table 4.

Table 4. Error correction model estimation results

\begin{tabular}{|c|c|c|c|c|}
\hline Variable & Coefficient & Std. Error & t-Statistic & Prob. \\
\hline C & 0.015438 & 0.009921 & 1.556178 & 0.1313 \\
\hline D(LNDINC) & 0.719185 & 0.083605 & 8.602220 & 0.0000 \\
\hline ECM(-1) & -0.141483 & 0.216813 & -0.652559 & 0.5196 \\
\hline R-squared & 0.734283 & \multicolumn{2}{|c|}{ Mean dependent var } & 0.093089 \\
\hline Adjusted R-squared & 0.714601 & \multicolumn{2}{|c|}{ S.D. dependent var } & 0.042166 \\
\hline Log likelihood & 72.80463 & \multicolumn{2}{|c|}{ F-statistic } & 37.30598 \\
\hline Durbin-Watson stat & 1.145691 & \multicolumn{2}{|c|}{ Prob(F-statistic) } & 0.000000 \\
\hline
\end{tabular}

From the Table 4, the $\mathrm{P}$ value of the model estimation F statistics is very small, $\hat{R^{2}}=0.734$. It shows that the overall model estimates are significant. In addition, the coefficient estimates of $\Delta \ln$ Dinc $_{t}$ are significant, implying the short-run elasticity of consumption spending to income. At the $10 \%$ test level, the coefficient estimates of the error correction terms ecm $(-1)$ are significantly. The coefficient can react the adjustment of consumption away from the long term equilibrium. The greater the absolute value of the coefficient is, the faster the non-equilibrium state is restored to equilibrium state [8]. If $e c m(-1)$ is estimated to be $0, \ln A C S_{t}$ and $\ln$ Dinc $_{t}$ adjust in the same period immediately.

Therefore, the estimation results of the error correction model are bellow.

$\Delta \ln A_{C S}=0.0154+0.7192 \Delta \ln$ Dinc $_{t}-0.1414 e c m_{t}$

Using the estimated model, we can analyze the short-term change of consumption spending. There are two reasons for consumption spending change. One is that the short-term income changes. The 
other is consumer spending of previous period deviates from the long-term equilibrium[9]. If $e c m_{t-1}=0$, the previous period consumption does not deviate from the long-term equilibrium. So, the current consumption spending change is caused by real disposable income. If $e^{e c m_{t-1}} \neq 0$, the previous period of consumption deviates from the long-run equilibrium.In order to maintain the longrun equilibrium relationship between real consumption spending and disposable income, the current consumption spending will be at the rate of -0.14148 (i.e., the coefficient estimates of the error correction) to adjust the imbalance between consumption and income in the previous period.

\section{Granger causality test}

We use Granger causality test to test the causal relationship between variables. After multiple experiments, we choose 2 as the lag period. And make lnACS and lnDinc Granger causality test, the results are shown in table 5.

Table 5. Granger causality test result

\begin{tabular}{|c|c|c|c|}
\hline Null Hypothesis: & Obs & F-Statistic & Probability \\
\hline \multicolumn{2}{|c|}{ InDinc does not Granger Cause $\operatorname{lnACS} 33$} & 0.80168 & 0.45860 \\
\hline $\operatorname{lnACS}$ does not & e $\ln$ Dinc & 0.73631 & 0.48792 \\
\hline
\end{tabular}

As seen from Table5, at the 10\% significant level, disposable income is the Granger cause of actual consumption spending. Conversely, actual consumption spending is not the Granger cause of disposable income. In other words, actual disposable income has a positive effect on consumption spending, but actual consumption spending has little effect on disposable income.

\section{Summary}

Through the empirical research above, there is a long-term equilibrium relationship between real disposable income and real consumption spending. Granger causality tests indicates disposable income stimulates actual consumption spending significantly, but actual consumption spending has little effect on disposable income. The disposable income of residents has increased in recent years, and it has a significant effect on the actual consumption spending. But it still not reaches the ideal state, and the effect of consumption on demand is blocked.

\section{References}

[1]. Tian Qing. Integrative Test of Relation between Urban Residents' Income and Their Consumption in China [J].Consumer Economics,2008,(03):7-10

[2]. Liu Liying. Empirical Analysis on The Short-term Dynamics and Long-run Equilibrium Relationship of Rural People's Incomes and Spending [J].Journal of Anhui Agricultural Sciences | J Anhui Agric Sci, 2010, (19):10349-10350+10414.

[3]. Wang Mingxing. An empirical analysis of the relationship between consumption and income of urban residents in Shaanxi Province [J].Journal of Shanghai Business School, 2013, (01):45-48.

[4]. Liao Yong. An empirical study on the relationship between income and consumption of rural residents in Sichuan province from the perspective of public finance [D].Southwestern University of Finance and Economics, 2014.

[5]. Liu Lingzhi,Xiao bangming, Wang Yapeng. A study on the long term equilibrium and short term dynamic relationship between wage income and living expenditure of rural residents [J]. Statistics and Decision, 2012, (17):93-95.

[6]. Liu Donghuang,Shen kunrong. Factor distribution, income gap and consumption growth [J]. Economic Perspectives, 2012, (10):47-52.

[7]. Cao Yu,Chen Xiaohong, Ma Yueru Urbanization, urban-rural income gap and economic growth: An Empirical Study Based on Provincial Panel Data in China[J].Statistical Research, 2010, (03):29-36. 
[8]. Jiang Tao,Du Liangsheng. An empirical analysis of the relationship between income gap and economic growth of urban residents in China_based on E-G Two-step method [J]. Macroeconomics, 2014, (03):114-124.

[9]. Sun Pengjun. Research on the imbalance of Chinese residents' consumption and the distribution of national income [D].Fudan University, 2012. 